\title{
DISPOSITIVOS AUDIOVISUAIS NA EDUCOMUNICAÇÃO SOCIOAMBIENTAL ESCOLAR: EXPLORAÇÕES POLÍTICAS E ESTÉTICAS
}

\author{
Marcus Staudt ${ }^{1}$ \\ Jane Mazzarino²
}

Resumo: Este artigo reflete sobre o uso do audiovisual em processos de educomunicação socioambiental escolar. Quais os desafios e as potencialidades que o uso destes dispositivos midiáticos em processos de educomunicação socioambiental apresentam? Busca-se resposta a esta questão utilizando-se o método bibliográfico. Abordam-se as contribuições da educomunicação socioambiental na Educação Ambiental, a educomunicação como uma estratégia de sedução no espaço escolar, o audiovisual como um desafio para professores e sua potencialidade pedagógica. Conclui-se essa abordagem como sendo um exercício político por meio de dispositivos que exploram a criatividade, a ludicidade e a construção da sustentabilidade no espaço escolar.

Palavras-chave: Educomunicação Socioambiental; Ambiente Escolar; Audiovisual; Estudo Bibliográfico.

${ }^{1}$ Centro Universitário Univates - Univates. E-mail: mstaudt@univates.br

${ }^{2}$ Centro Universitário Univates - Univates. E-mail: janemazzarino@gmail.com

Revbea, São Paulo, V. 11, № 1: 157-172, 2016.

revista brasileira educação ambiental 


\section{Introdução}

O objetivo do artigo é refletir sobre o uso do audiovisual em processos de educomunicação socioambiental escolar. O problema que conduz a reflexão, realizada por meio do método bibliográfico, refere-se à compreensão de quais os desafios e as potencialidades que o uso destes dispositivos midiáticos em processos de educomunicação socioambiental apresentam. A educomunicação é um campo de intervenção social relativamente novo. O termo começou a ser utilizado entre as décadas de 1970 e 1980 por Mario Kaplún. Na década de 80 , houve uma preocupação internacional com a educação para a recepção dos produtos midiáticos e, após dez anos, métodos de abordagem para prática de educação para a mídia ganharam destaque no Brasil. Em 1996 surgiu o Núcleo de Comunicação e Educação (NCE), órgão da Universidade de São Paulo (USP) que definiu o campo da educomunicação como sendo um:

[...] espaço que membros da sociedade se encontram para implementar ecossistemas comunicativos democráticos, abertos e participativos, impregnados da intencionalidade educativa e voltado para a implementação dos direitos humanos, especialmente o direito à comunicação (NCE/USP apud SANTOS, 2013, p.2). ${ }^{3}$

Martín-Barbero (2011) explica que os conhecimentos adquiridos no ecossistema comunicativo são feitos de mosaicos de saberes, isto porque referem-se a fluxos de relações dos grupos humanos e, também, com os canais de acesso de todas as pessoas às tecnologias da informação. As tecnologias são consideradas "parte das mediações que a cultura contemporânea apresenta para garantir as formas de expressão" (SOARES, 2012a). Já os ecossistemas comunicativos são caracterizados por Citelli (2011) como todos os circuitos de retroalimentação, "desde o plano da produção material, passando pelas estratégias de composição e circulação das mensagens".

Para Martín-Barbero (2011, p.123) é preciso reconhecer o papel fundamental que o conhecimento e a informação tem na sociedade, assim como o modo que afetam processos de desenvolvimento econômico, de democratização política e social. De modo complementar, Orozco-Gómez

\footnotetext{
3 Os documentos nacionais norteadores desta área prevê em seis dimensões e seis sub-áreas para educomunicação. As dimensões são: como campo de conhecimento, para recepção crítica dos conteúdos da comunicação de massa; espaço educativo irradiador de processos de educomunicação; gestão participativa dos meios; processos formativos de habilidades comunicativas; e a dimensão da educação em relação aos meios de comunicação de massa (BRASIL, 2005 e 2008). As sub-áreas são: educação para comunicação (ambas entendidas a partir da perspectiva da interação social); mediação tecnológica (vinculada à presença de tecnologias no processo); gestão da comunicação no espaço educativo (envolve planejamento, execução e avaliação do processo); reflexão epistemológica (estudos, especialmente acadêmicos, na área), expressão comunicativa através de artes (capacidade criativa, exploração imagética) e a pedagogia da comunicação (intervenção, didática) (BRASIL, 2008).
}

Revbea, São Paulo, V. 11, No 1: 157-172, 2016. 
(2011) defende que as tecnologias e comunicação podem auxiliar na democratização tanto da educação como da comunicação, e, consequentemente, do conhecimento.

Entende-se, desse modo, que a educomunicação é um campo transformador e crítico, que objetiva o desenvolvimento social com cidadãos ativos, protagonistas na produção do conhecimento e de aprendizagem, por meio de processos que incluem o uso de mídias, mas também afetividade, cooperação, participação, livre expressão, interatividade e experimentação (ROSA, 2014; SAYAD, 2011; MIRANDA, 2006).

\section{Método}

A pesquisa é bibliográfica. Selecionaram-se argumentos considerados mais relevantes para a construção do artigo após coleta em livros e artigos científicos sobre educomunicação, a educomunicação socioambiental, a Educação Ambiental e os dispositivos audiovisuais.

Segundo Gil (2006, p.44), "a principal vantagem da pesquisa bibliográfica reside no fato de permitir ao investigador a cobertura de uma gama de fenômenos muito mais ampla do que aquele que poderia pesquisar diretamente". Para que fosse possível expandir o embasamento desse estudo foi realizada uma busca por trabalhos publicados entre 2005 e 2014 nos seguintes portais científicos: da Asociación Latinoamericana de Investigadores de la Comunicación (Alaic), da Sociedade Brasileira de Estudos Interdisciplinares da Comunicação (Intercom), da Associação Nacional dos Programas de Pós-Graduação em Comunicação (Compos), da Coordenação de Aperfeiçoamento de Pessoal de Nível Superior (Capes) e Scielo.

Portanto, a fundamentação teórica é resultado da consulta a diferentes fontes sobre o assunto, passando por teóricos clássicos até trabalhos mais recentes de pesquisadores (AMARAL, 2007).

A coleta foi realizada através do próprio campo de pesquisa existente nos sites em questão, com a palavra-chave: educomunicação. Após, criou-se uma sistematização em forma de tabela. Os materiais coletados foram fichados e as ideias organizadas nos capítulos que seguem.

\section{Contribuições da educomunicação socioambiental na Educação Ambiental}

Tratar da educomunicação socioambiental é um modo de contemplar, nos ambientes escolares, formas de abordar a relação entre sociedade e natureza através de metodologias que privilegiam a horizontalidade, colocando educadores e educandos em um mesmo grau de hierarquia. Trabalhar com essa ideia no âmbito escolar pode favorecer o aprendizado e a constituição de cidadãos críticos, por meio de um processo dinâmico e participativo, potencializando-se atitudes futuras mais conscientes, colaborativas e de cooperação com o meio ambiente.

revista brasileira educação ambiental 
A educomunicação socioambiental, um subcampo da área da educomunicação, surge a partir da I Oficina Nacional de Comunicação e Educação Ambiental, promovida pelo Departamento de Educação Ambiental (DEA) do Ministério do Meio Ambiente (MMA), em 2004, em Brasília. O debate decorrente deste evento vai determinar a criação do Programa de Educomunicação Socioambiental pelo Órgão Gestor da Política Nacional de Educação Ambiental, em 2005 (BRASIL, 2005).

As principais referências da educomunicação socioambiental são, ainda, o Programa de Educomunicação Socioambiental e 0 documento Educomunicação socioambiental: comunicação popular e educação, produzidos principalmente por teóricos ligados ao Núcleo de Comunicação e Educação (NCE), da Universidade de São Paulo (USP), ou influenciados por estes.

O documento Educomunicação socioambiental: comunicação popular e educação, publicado em 2008 vai definir a educomunicação socioambiental como:

A Educomunicação Ambiental ou Socioambiental é uma expressão nova que vem ganhando espaço no campo da Educação Ambiental, nos últimos anos. Refere-se ao conjunto de ações e valores que correspondem à dimensão pedagógica dos processos comunicativos ambientais, marcados pelo dialogismo, pela participação e pelo trabalho coletivo. A indissociabilidade entre questões sociais e ambientais no fazerpensar dos atos educativos e comunicativos é ressaltada pelo termo socioambiental. A dimensão pedagógica, nesse caso em particular, tem foco no "como" se gera os saberes e "o que" se aprende na produção cultural, na interação social e com a natureza (BRASIL, 2008).

Os princípios da educomunicação socioambiental são, em síntese, a) dialogia; b) compromisso com a interatividade e produção participativa de conteúdos, sem necessariamente haver o domínio da tecnologia e de alguma forma de saber; c) a transversalidade, que requer o envolvimento de outros campos de saber em processos multimídia; d) o encontro/diálogo de saberes de diferentes atores; e) o compromisso com a proteção e valorização do conhecimento tradicional e popular; f) a democratização da comunicação, com acesso à informação socioambiental, aos meios de produção e à gestão participativa; g) o compromisso com o direito à comunicação enquanto direito humano; h) o respeito à individualidade e diversidade humana, mantendo linguagens inclusivas, nunca discriminatórias (BRASIL, 2008).

Estes princípios encontram-se com pressupostos hegemônicos do campo da Educação Ambiental. A educomunicação socioambiental, no entanto, localiza-se como parte do campo da Educação Ambiental, referindo-se especificamente à dimensão pedagógica dos processos comunicativos 
voltados para a construção de uma cultura da sustentabilidade. A educomunicação socioambiental se diferencia da Educação Ambiental, porque esta privilegia aspectos educativos sem colocar em primeiro plano a dimensão comunicacional.

A Educação Ambiental surge preocupada exclusivamente com os recursos naturais finitos e a distribuição dos mesmos, além de querer unir a população em ações sociais ambientais "corretas". Fortemente influenciada pelos movimentos sociais e ambientais que nasceram nos anos 60 e 70 , a Educação Ambiental foi disseminada como um campo que conversa com a Educação, mas mantém conceitos e teorias próprias (CARVALHO, 2008).

Decorrente do processo histórico do campo ambiental, diversos planos e propostas foram discutidas pelo mundo com o intuito de criar políticas públicas para Educação Ambiental, especialmente decorrente das conferências promovidas pela Organização das Nações Unidas (ONU) ${ }^{4}$. Mas é desde a Conferência das Nações Unidas sobre o Meio Ambiente e o Desenvolvimento, a Rio-92, que estes temas estão em evidência, seja porque a mídia os explora ou em função da necessidade de se minimizar problemas vinculados aos impactos ambientais.

A regulamentação da Educação Ambiental no país se dá através da Lei $n^{\circ}$ 9.795, de abril de 1999, a Política Nacional de Educação Ambiental (PNEA). De acordo com o primeiro capítulo da Lei:

Entendem-se por Educação Ambiental os processos por meio dos quais o indivíduo e a coletividade constroem valores sociais, conhecimentos, habilidades, atitudes e competências voltadas para a conservação do meio ambiente, bem de uso comum do povo, essencial à sadia qualidade de vida e sua sustentabilidade (BRASIL, 1999).

A Educação Ambiental no âmbito formal também está nos Parâmetros Curriculares Nacionais (PCN), que aponta diretrizes para trabalhar questões ambientais no âmbito escolar, independentemente de ser em nível de Ensino Básico ou Médio. O documento, que serve como ajuda para a escola cumprir seu papel de fortalecimento da cidadania, reconhece a importância que os meios de comunicação têm na abordagem das informações referentes ao meio ambiente, fomentando o debate e transformações sociais (BRASIL, 1997).

Para Carvalho (2008, p.158) é necessário uma Educação Ambiental crítica, na qual escola e comunidade trabalhem na sensibilização da sociedade quanto à crise ambiental, considerando a urgência de se mudarem padrões

\footnotetext{
4 Em 1972, na cidade de Estocolmo, na Suécia, aconteceu a I Conferência Internacional sobre Meio Ambiente. Já no ano de 1977, em Tbilisi, na antiga União Soviética, ocorreu a I Conferência sobre Educação Ambiental. E no ano de 1997, na Grécia, Tessalônica foi à sede da segunda edição do evento, realizado em 1977.
}

revista brasileira educação ambiental 
comportamentais. Trata-se de: "[...] um movimento que busca produzir novo ponto de equilíbrio, nova relação de reciprocidade, entre as necessidades sociais e ambientais".

E neste fazer, que a educomunicação socioambiental em espaços escolares tem vasta possibilidade de contribuir, já que busca 0 desenvolvimento socioambiental para o protagonismo dos participantes por meio de processos de aprendizagem dialógicos, interativos, transversais e democráticos, que incluem o uso de tecnologias de comunicação.

\section{Educomunicação no espaço escolar: uma estratégia de sedução}

A interferência das mídias na cultura redimensiona as potencialidades da escola, solicitando uma discussão pedagógica dessas relações, segundo Fantin (2006). Já Baccega reforça a teoria de que os meios de comunicação de massa servem para auxiliar o espaço escolar e que se distanciar dos mesmos só impede as escolas de criar novos conhecimentos:

[...] enquanto a escola continua com sua retórica pedagógica conservadora, ocupando todo o tempo de sala de aula com esse discurso, o discurso dos meios de comunicação está presente no âmbito da escola, de maneira clandestina. Não adentram as salas de aula, mas estão nos corredores, nos intervalos, nas conversas informais, tanto de professores quanto de alunos. É urgente que esses discursos outros saiam da clandestinidade e passem a constituir parte dos diálogos que deveriam ocorrer em sala de aula (BACCEGA, 2000, p. 61 apud ALMEIDA, 2006, p.3).

Em relação ao uso pedagógico dos meios nos ambientes escolares, Kaplún é direto:

No que diz respeito ao emprego de meios na educação, bemvindos sejam, desde que aplicados crítica e criativamente, a serviço de um projeto pedagógico, ultrapassando a mera racionalidade tecnológica; como meios de comunicação e não de simples transmissão; como promotores do diálogo e da participação; para gerar e potenciar novos emissores mais que para continuar fazendo crescer a multidão de receptores passivos. Enfim, não meios que falam, e sim meios para falar (KAPLUN, 2011, p.184). 
[...] por meio do audiovisual no ambiente escolar pode-se incentivar o protagonismo juvenil, ou seja, fazer com que aquele que aprende sobre a técnica e a linguagem audiovisual amplie sua visão de social e promova mudanças na sua comunidade" (CASSOL, et al. 2011, p.6).

Também Assumpção (2006) refere-se aos meios midiáticos como opções para o desenvolvimento das linguagens que seduzem de forma agradável no espaço escolar, mas ainda são pouco utilizados. Assim, as tecnologias externas às escolas não podem ser ocultadas e renegadas pelo grupo docente das escolas, pois estes saberes influenciam o cotidiano do aluno e do professor. Segundo o mesmo autor, colocar o corpo estudantil para confeccionar conteúdo comunicacional em um ambiente escolar proporciona desenvolvimento de habilidades produtivas, além de conscientizar os jovens do seu papel como cidadão.

Quando se possibilita que os próprios alunos, de forma independente, tornem-se disseminadores das informações, pode gerar a percepção de enfraquecimento da imagem de autoridade do educador diante do jovem, já que este tende a ter mais facilidade na interação com as tecnologias. No caso do uso de dispositivos audiovisuais em processos educativos é um desafio aos professores, mas, ao mesmo tempo, se coloca como uma aposta metodológica diferenciada para o espaço escolar, que pode oportunizar aprendizados lúdicos, criativos e despertadores de novas sensibilidades.

No entanto, ao se optar pelas novas tecnologias é preciso estar ciente que os meios não irão "salvar" o modelo pedagógico, pois precisam de uma abordagem pedagógica para que possam servir na escola para exercícios reflexivos, proporcionando interpretação e a compreensão de mensagens, conceitos e informações (LEAL, 2012, p. 5). Isto porque é preciso perceber que esse jogo entre o que se percebe da comunicação midiática, concentrada nas ideias recebidas pelo cidadão até 0 que se retransmite após esse conhecimento adquirido faz parte de um processo que "irá se modificar com a interação de novas comunicações e, dessa forma, irá modificar novas mensagens recebidas e também o sujeito em si mesmo" (ANNIBAL E LEPRE, 2013, p.4).

Neste processo contínuo de ressignificação, o audiovisual constitui-se em uma estratégia sedutora para jovens em ambiente escolar. Por isso não deve ser tratado como somente uma oportunidade motivacional para os estudantes, mas também um momento de atualização de fontes de aprendizado, levando em consideração o fato de que é necessário um apoio específico para se utilizar esse meio (NAPOLITANO, 2002, p.11).

Citelli (2011, texto digital) defende que os dispositivos audiovisuais precisam ser usados em favor da educomunicação, auxiliando o desenvolvimento dos estudantes. Segundo ele, é preciso experimentar esses recursos e, assim, saber como usá-los "para finalidades educativas ou por

revista brasileira educação ambiental 
outro lado, como é que a educação pode colaborar para tornar a comunicação, digamos, de mais interesse da comunidade, do cidadão e do interesse público".

Segundo Vasconcelos (2012, p.113), independentemente de quais os meios utilizados, o importante é a forma como o professor comunica-se com os alunos. A comunicação deve ser carregada de intencionalidade, de valores e de significação. Orozco-Gómez (2011, p.160) afirma que mesmo tendo a tecnologia ao alcance, o importante é não se restringir a somente tê-las para não tornar-se dependente delas, já que o importante é "aproveitar o potencial da tecnologia para nossos próprios fins e de acordo com as nossas peculiaridades culturais, científicas e tecnológicas".

No entanto, para que essa mesma sociedade consiga estabelecer espaços para o desenvolvimento desses conhecimentos é necessário que existam docentes preparados para este desafio ou dispostos a prepararem-se para ele. Sartori entende que os professores precisam aprender a lidar com as novas tecnologias e compreender que não são simplesmente transmissores de informação, pois só assim será possível desenvolver práticas pedagógicas direcionadas para o conhecimento. Desse modo, o educador vai exercitar novas linguagens e problematizar a realidade:

$\mathrm{Na}$ atualidade, é fundamental investir numa formação de professores que alie as concepções pedagógicas contemporâneas, que apontam o docente como um mediador, responsável em organizar situações de aprendizagem baseadas em problemas e na interdisciplinaridade, dentre tantas outras características [...] (SARTORI, 2011, p.12).

Corazza (2013, p.1) faz o seguinte questionamento: "em que medida os educadores conseguem acompanhar esse ritmo de crianças e jovens e ter um universo comum para se comunicarem no campo educativo?". A própria autora entende que responder a essa pergunta através da apropriação das novas tecnologias é um passo fundamental: "[...] para que aconteça mudança também nas linguagens e métodos de ensino no dia a dia" (CORAZZA, 2013, p.2).

Mogadouro e Soares (2011, p.275) relatam a experiência de acompanhar o uso da linguagem cinematográfica em sala de aula e o medo que educadores mostraram com os avanços tecnológicos: "[...] percebemos, principalmente, a enorme insegurança dos professores em virtude da ausência de formação audiovisual". Os autores explicam que os espaços escolares mantêm um padrão tradicional, "[...] com conteúdos fragmentados, gestão autoritária, desvalorização do professor e uma exigência na relação professor/aluno, em que o primeiro ainda é o transmissor do saber". Mas, segundo Mogadouro e Soares (2011, p.275), quando se utiliza o audiovisual, em diversos casos, os educandos sabem mais do que o educador, o que fortalece a insegurança do professor. Além disso, há os temas discutidos nesse contexto, que em inúmeros casos são assuntos complexos para os docentes abordarem, como sexualidade, violência e consumo.

Revbea, São Paulo, V. 11, № 1: 157-172, 2016. 
A educomunicação ganha ou ganhará espaço no ambiente escolar a partir do momento em que a educação concebe novas frentes, ou seja, deixa de ter somente o ensino ofertado ao estudante dentro da lógica de única direção, na qual o educador repassa conteúdo e o estudante é um agente passivo. A educomunicação coloca-se como espaço de construção crítica com mediação tecnológica, tornando-se, assim, uma forma complementar do programa escolar (CASSOL, et al. 2011).

Coerente com essa ideia, Almeida (2011, p.2) considera que a construção da educação alicerçada no senso crítico precisa existir desde as séries iniciais nos ambientes escolares e que a televisão é parte desse processo. Ela é onipresente no cotidiano social brasileiro. Contudo, muitos educadores perderam (ou ainda perdem) a oportunidade de poder utilizar esses elementos para dinamizar o ambiente de ensino, avaliam Xavier e Soledade (2013).

Cassol et al. (2011, p.5) afirmam que o audiovisual é uma ferramenta extraordinária, "fundamental para o processo de conscientização, formação de opiniões, mobilização, exercício da cidadania e para a construção de uma identidade social'. Oliveira e Gonçalves (2008, p.13) entendem que especificamente na educomunicação, o audiovisual possibilita ao indivíduo transformar e dar um norte quanto a sua percepção de mundo, capacitá-lo à compreensão do que lhe é informado, e dá-lhe a possibilidade de observar o ambiente e saber distinguir representações para uma vida mais consciente. Trata-se de um processo de alfabetização audiovisual: "um estímulo ao pensamento, favorecendo, assim, o crescimento da vontade de saber mais".

$\mathrm{O}$ recurso audiovisual em um processo educomunicativo escolar tem a vantagem de ser atrativo para diversos públicos, um meio propício para repassar conteúdos aos estudantes e estimulante do pensamento, segundo Cassol et al. (2011): "Uma pessoa com conhecimentos sobre essa ferramenta pode impactar a comunidade onde está inserida, influenciando visões e sentimentos, podendo, assim, ajudar a mudar e a melhorar a realidade" (CASSOL, et al. 2011, p.5). É preciso ter em conta, no entanto, as diferenças de acesso às tecnologias que possibilitam a construção audiovisual: câmeras e ilhas de edição são necessárias:

Em escolas privadas, as condições de utilização dos recursos multimídias são melhores. Geralmente, as escolas privadas possuem laboratórios de informática, salas de vídeo confortáveis e disciplinas que debatem os rumos da sociedade contemporânea, como a disciplina de Atualidades. Já nas escolas públicas, a realidade é bem diferente. Em boa parte delas, os recursos audiovisuais não existem, os professores sentem-se desmotivados pelos baixos salários e pela carga horária excessiva, os alunos sentem dificuldades em disciplinas básicas (como Português e Matemática) e a infraestrutura das escolas deixa a desejar (XAVIER E SOLEDADE, 2013, p.4). 
No entanto, a Lei de Diretrizes e Bases $n^{\circ} 9.394$, de 20 de dezembro de 1996, no Art. 36, além de providências relacionadas à inclusão de línguas estrangeiras e filosóficas no ambiente escolar, estimula o uso das tecnologias,

I - destacará a educação tecnológica básica, a compreensão do significado da ciência, das letras e das artes; o processo histórico de transformação da sociedade e da cultura; a língua portuguesa como instrumento de comunicação, acesso ao conhecimento e exercício da cidadania (BRASIL, 1996).

Segundo Xavier e Soledade (2013, p.4) o Ministério da Educação distribuiu em todo o país um kit tecnológico (com TV, vídeo e antena parabólica), mas muitas escolas afirmam nunca ter recebido ou utilizado. No entanto, mesmo as escolas que tiveram acesso a tecnologias, necessariamente não foram usados em processos educomunicativos. Mais comum parece ser encontrar esses materiais engavetados para o uso de registro de eventos da instituição, como evidenciamos em escolas.

Quando potencializam processos educomunicativos, podem surpreender. A partir de uma oficina de vídeo com o intuito de facilitar o acesso à tecnologia e a informação, Oliveira e Gonçalves (2008, p.14) perceberam que o audiovisual acaba sensibilizando a percepção "a favor do conhecimento e da democracia". $\mathrm{E}$, além disso, conseguem não só levar ensinamentos para os participantes como também formar novos comunicadores, independente de idades.

Oliveira e Gonçalves (2008, p.2) analisaram a experiência de educomunicação audiovisual em dois projetos nessa área, no Estado de São Paulo, que trabalhavam com produções de curtas-metragens. Eles questionavam-se "como a Educomunicação audiovisual pode formar olhares adolescentes menos alienados pela televisão, tornando-os mais críticos e objetivos na busca do conhecimento científico?'. Ao fim, chegaram à conclusão que a oficina de vídeo demonstrou ser um instrumento facilitador e qualificador da transformação social.

E porque optar pelo audiovisual em meio a uma era em que existem tantos outros mecanismos de disseminação de informações, como a revista, o jornal, o rádio e a internet? Xavier e Soledade (2013, p.7) consideram que a televisão tem grande força na sociedade, independente de faixa etária ou qualquer outra forma de categorização de público. Este meio "altera formas de convivência e ressignifica olhares sobre o mundo". Por meio desta estratégia consegue-se criar um ambiente estimulador de situações significativas de aprendizagem, já que as propostas inovadoras desafiam as crianças, afirma Matarazzo (2014).

Para Annibal e Lepre $(2013$, p.10) a fusão da comunicação com a educação possibilita uma via de arejamento na utilização dos recursos, 
linguagens e na reconfiguração do espaço educacional, "oportunidade, talvez, de protagonismo dos alunos e professores, além de uma revisão das representações e usos da escola".

\section{O audiovisual na educomunicação socioambiental}

A utilização dos meios audiovisuais como auxílio pedagógico em processos de educomunicação socioambiental é importante em suas diversas formas e roupagens, ou seja, inúmeros meios audiovisuais podem ser usados para disseminarem, em plataformas tradicionais ou não, os conteúdos ambientais, como é o caso de documentários. Estes produtos também podem ser veiculados por meios virtuais, que compensam no alto alcance e impacto. "Circulantes na internet por meio das múltiplas redes em conexão, tais produções, quase sempre, escapam aos domínios de poder tradicionais e engendram uma nova estratégia de militância ambiental [...]" (FALCÃO; ALMEIDA; CITELLI, 2012, p.4). Para Costa (2014, p.325) a produção audiovisual de diferentes vertentes e por vários atores deixa emergir significados construídos sobre a questão socioambiental.

Segundo Falcão, Almeida e Citelli (2012, p.4), materiais audiovisuais que tem o intuito de tentar reverter danos socioambientais, quando construídos por meio de diversos olhares e são exibidos e compartilhados através da horizontalidade do mundo virtual "[...] lançam luzes de vários matizes sobre $o$ descaso com que temos tratado o meio ambiente no plano micro e macro de nossa experiência cotidiana". Porém, em relação aos efeitos na sociedade, os autores pontuam obstáculos para a difusão destas produções. Para estes autores, nos círculos comerciais, eles praticamente não chegam, em razão de interesses financeiros. No ambiente escolar esse recurso transita. Todavia, não se sabe o potencial de sensibilização que ele pode causar para tornar cidadãos mais proativos e críticos (FALCÃO; ALMEIDA; CITELLI, 2012). Em relação a este aspecto, Costa (2014) relata os resultados e o que foi projetado de sua pesquisa com um grupo de moradores que viviam em uma região afetada pelos impactos ambientais e que participaram de uma oficina audiovisual socioambiental com enfoque na educomunicação: conceitos foram incorporados $e$ as pessoas envolvidas no processo educomunicativo conseguiram se apropriar das temáticas trabalhadas.

Segundo Falcão, Almeida e Citelli (2012, p.6), existe um interesse cada vez maior por peças audiovisuais que buscam a reversão do desrespeito que 0 meio ambiente sofre. E como estes materiais não acessam salas cinematográficas porque perdem espaço para filmes que atendem aos padrões de mercado, a internet torna-se um alicerce para a sustentação e disseminação desses vídeos. As produções audiovisuais podem ser veiculadas pelas redes sociais e pelas plataformas digitais acessíveis, como Youtube.

Outra possibilidade que acaba facilitando o acesso a essas produções para posterior postagem nos espaços digitais é a mobilidade, em vídeos 
produzidos a partir de plataformas dessas novas mídias, como por exemplo, os celulares.

Em relação aos documentários, quando em formatos inovadores, tem condições: "[...] de reverter a desatenção coletiva sobre os problemas relacionados ao consumo desmesurado e à consequente deterioração das condições da vida planetária" (FALCÃO; ALMEIDA; CITELLI, 2012). Estes autores salientam que as redes sociais são um espaço estratégico para desviar da tentativa de controle e dominação que os meios tradicionais impõem.

Independente do gênero (documentário, matéria telejornalística etc.), do tamanho, ou da forma de veiculação dessas produções, o importante é que no processo de construção dos audiovisuais não se perca o foco educomunicativo para trabalhar os temas socioambientais.

\section{Conclusões}

A partir das reflexões realizadas ao longo do artigo, podem ser pontuados alguns desafios e possibilidades do uso de dispositivos audiovisuais na educomunicação socioambiental.

Identificam-se como desafios: a apropriação da linguagem audiovisual por professores, a mediação do processo educomunicativo, o exercício do papel do educomunicador respeitando os princípios da educomunicação socioambiental, a mediação de conflitos decorrentes do processo de interação que se estabelece, a estimulação do protagonismo dos participantes, a garantia da horizontalidade entre professores e alunos, a escolha das temáticas e seus modos de abordagem em termos de conteúdo e gênero/formatos, a exploração da diversidade de opções que as tecnologias oferecem em termos de linguagem audiovisual, capacitar professores para atuar como educomunicadores, o respeito aos diferentes ritmos de aprendizado dos participantes, a inclusão da educomunicação no currículo, o respeito à diversidade de saberes, a garantia da acessibilidade aos dispositivos (obter os equipamentos) e o estímulo ao seu uso com a finalidade pedagógica, a compreensão dos participantes do que é um processo educomunicativo, o entendimento que no processo educomunicativo é preciso estar aberto a mudanças de rumo ao longo de seu percurso, a garantia que a educação seja comunicativa (troca) e não apenas informativa, ser interdisciplinar, manter o equilíbrio entre a sedução das tecnologias com a sedução das temáticas ambientais.

Como potencialidades identificam-se: 0 fascínio que as novas tecnologias exercem entre jovens, as possiblidades de seu uso criativo em experimentações livres que estimulam a ludicidade, a democratização no acesso às mídias e do direito à comunicação, o desenvolvimento do espírito crítico em relação à produção midiática e à problemática ambiental, o desenvolvimento de novas narrativas e habilidades comunicativas, o poder de impactar culturalmente a sociedade por meio da disseminação ampla das produções via redes sociais e canais próprios (Youtube, facebook e celular), o Revbea, São Paulo, V. 11, № 1: 157-172, 2016. 
acesso crescente às novas tecnologias de produção e disseminação de conteúdos, a criação de novos conhecimentos, a força que tem como uma metodologia de ensino inovadora e o poder de renovar o ânimo dos envolvidos no processo pedagógico.

A educomunicação socioambiental com uso dos audiovisuais se propõem a ser um exercício político por meio de dispositivos que exploram a criatividade, a ludicidade, as linguagens e a estéticas visual e, assim, potencializa a sensibilização ambiental dos envolvidos e a construção da sustentabilidade no espaço escolar.

Mas para se estabelecer um processo de educomunicação faz-se necessária uma abordagem horizontal, o que em um contexto escolar requer que professores e alunos percebam-se parte de um aprendizado coletivo. Uns e outros precisam demonstrar receptividade para a proposta educomunicativa no ambiente escolar para ela poder ser melhor explorada como um elemento de construção do conhecimento, de transformação, de desenvolvimento da criticidade e da autonomia, de compartilhamento de ideias, de democratização da comunicação e de aprendizagem criativa.

O caminho pedagógico apontado por Barcelos (2012, p.83) a ser trilhado na educação e na Educação Ambiental em especial, pode ser apropriado para a educomunicação socioambiental escolar, já que, necessariamente, precisa do envolvimento e da entrega dos professores que irão desenvolver os projetos junto aos educandos. Para o autor, as alternativas metodológicas "precisam de um envolvimento afetivo, lúdico, amoroso, de todos aqueles que a ela se dedicam, sob pena de a transformarmos em mais uma mera tarefa a ser cumprida".

\section{Referências}

ALMEIDA, A.L. Mídia, educação e cidadania na Aldeia Global: para que mundo estamos educando. 2006. Disponível em: $<$ http://www.unirevista.unisinos.br/ pdf/UNIrev Almeida.PDF>. Acesso em: 10 maio 2014.

ALMEIDA, R. O vídeo na educação infantil: os impactos do uso do vídeo nas práticas educativas. In: XXXIV Congresso Brasileiro de Ciências da Comunicação - 2 a 6 de setembro de 2011. Anais... Recife, PE, set. 2011. Disponível em: <http://www.intercom.org.br/papers/nacionais/2011/resumos/R6-2687-1.pdf>.

Acesso em: 16 set. 2014.

AMARAL, J.J.F. Como fazer uma pesquisa bibliográfica. Fortaleza, 2007. Disponível em: <http://200.17.137.109:8081/xiscanoe/courses1/mentoring/tutoring/Como\%20fazer\%20pesquisa\%20bibliografica.pdf $>$. Acesso em: 28 ago. 2014. 
ANNIBAL, S.F.; LEPRE, L.R. Comunicação e educação: mídias e a formação de professores. In: XXXVI Congresso Brasileiro de Ciências da Comunicação - 4 a 7 de setembro de 2013. Anais... Manaus, AM, set. 2013. Disponível em: $<$ http://www.intercom.org.br/papers/nacionais/2013/resumos/R8-0745-1.pdf>.

Acesso em: 02 out. 2014.

ASSUMPÇÃO, Z.A. Radioescola: locus de cidadania, oralidade e escrita. 2006. Disponível em: <http://www.unirevista.unisinos.br/ pdf/UNIrev Assumpcao.PDF>. Acesso em: 27 maio 2014.

BRASIL. Educomunicação socioambiental: comunicação popular e educação. Organização. Francisco de Assis Morais da Costa. Brasília: MMA, 2008. Disponível em:

$<$ http://www.mma.gov.br/estruturas/educamb/ arquivos/txbase educom 20.pdf>.

Acesso em: 14 maio 2014.

BRASIL. Parâmetros curriculares nacionais: meio ambiente / Secretaria de Educação Fundamental. - Brasília: MEC/SEF, 1997. p.167-242. Disponível em: $<$ http://portal.mec.gov.br/seb/arquivos/pdf/meioambiente.pdf>. Acesso em: 02 set. 2014.

BRASIL. Programa de Educomunicação Socioambiental. Organização: Órgão Gestor da Política Nacional de Educação Ambiental: MMA, 2005. Disponível em: $<$ http://www.daep.com.br/coletivos/adm/download/dt 2 programa educomunicaca o socioambiental 4a versao maio final.pdf>. Acesso em: 12 ago. 2014.

CARVALHO, I.C.M. Educação Ambiental: a formação do sujeito ecológico. 4. ed. São Paulo: Cortez, 2008.

CASSOL, M.C. et al. Relatos da experiência da Oficina de Audiovisual "Educomunicação e o exercício da cidadania comunicativa". In: XXXIV Congresso Brasileiro de Ciências da Comunicação - 2 a 6 de setembro de 2011. Anais... Recife, PE, set. 2011. Disponível em: $<$ http://www.intercom.org.br/papers/nacionais/2011/resumos/R6-1330-1.pdf>.

Acesso em: 14 set. 2014.

CITELLI, A.O. Comunicação e educação: implicações contemporâneas. In: CITELLI, A.O.; COSTA, M.C.C. (Orgs.). Educomunicação: construindo uma nova área de conhecimento. São Paulo: Paulinas, 2011.

CITELLI, A.O. Educomunicação. Youtube, 2011. Disponível em: $<$ http://www.youtube.com/watch?v=ZdQLun-XCgA>. Acesso em: 17 maio 2014.

CITELLI, A.O. Meios de comunicação e Educação: Desafios para a formação de docentes. Revista ALAIC, n. 5, 2011. Disponível em: $<\mathrm{http}: / /$ www.alaic.net/revistaalaic/index.php/alaic/article/viewFile/11/11>. Acesso em: 15 jan. 2014.

CORAZZA, H. As novas tecnologias no citidiano de educadores e educadoras. In: XXXVI Congresso Brasileiro de Ciências da Comunicação - 4 a 7 de setembro de 2013. Anais... Manaus, AM, set 2013. Disponível em: <http://www.intercom.org.br/papers/nacionais/2013/resumos/R8-0212-1.pdf>.

Acesso em: 02 out. 2014. 
COSTA, R.N. Cinema e política ambiental nacional: o parque nacional da restinga de Jurubatiba e a indústria petrolífera em Macaé (RJ). In: V Encontro Brasileiro de Educomunicação: Educação midiática e políticas públicas - 19 a 21 de setembro de 2014. SOARES, Ismar de Oliveira Soares; VIANA, Claudemir Edson; XAVIER, Jurema Brasil (Orgs.). Anais... São Paulo: ABPEducom, p. 320-327, 2014. Disponível em: <http://www.abpeducom.org.br/2014/08/anais-do-v-encontrobrasileiro-de.html>. Acesso em: 16 out. 2014.

FALCÃO, S.P.; ALMEIDA, M.C.S.; CITELLI, A.O. Redes sociais e documentários: uso sinergético de dispositivos comunicacionais no debate socioambiental. In: XXXV Congresso Brasileiro de Ciências da Comunicação - 3 a 7 de setembro de 2012. Anais... Fortaleza, CE, set. 2012. Disponível em: $<$ http://www.intercom.org.br/sis/2012/resumos/R7-1479-1.pdf>. Acesso em: 16 set. 2014.

FANTIN, M. Mídia-educação: conceitos, experiências, diálogos Brasil-Itália. Florianópolis: Cidade Futura, 2006.

FREIRE, P. Pedagogia da autonomia: saberes necessários à prática educativa. 37. ed. São Paulo: Paz e Terra, 1996.

GIL, A.C. Como elaborar projetos de pesquisa. 4. ed. São Paulo: Atlas, 2006.

KAPLÚN, M. Processos educativos e canais de comunicação. In: CITELLI, A.O.; COSTA, M.C.C. (Orgs.). Educomunicação: construindo uma nova área de conhecimento. Anais... São Paulo: Paulinas, 2011.

LEAL, J.M. Comunicação e educação: o audiovisual Leonel Pé-de-Vento no espaço escolar e as possíveis significações construídas. In: XXXV Congresso Brasileiro de Ciências da Comunicação - 3 a 7 de setembro de 2012. Anais... Fortaleza, CE, $\quad$ set. 2012. Disponível em: $<$ http://www.intercom.org.br/sis/2012/resumos/R7-1479-1.pdf>. Acesso em: 16 set. 2014.

MARTÍN-BARBERO, J. Desafios culturais: da comunicação à educação. In: CITELLI, A.O.; COSTA, M.C.C. (Orgs.). Educomunicação: construindo uma nova área de conhecimento. São Paulo: Paulinas, 2011, p. 121-134.

MATARAZZO, G. Produção de curtas metragens por crianças de 5 e 6 anos. In: V Encontro Brasileiro de Educomunicação: Educação midiática e políticas públicas 19 a 21 de setembro de 2014. SOARES, I.O.S.; VIANA, C.E.; XAVIER, J.B (Orgs.). Anais... São Paulo: ABPEducom, p. 377-383, set. 2014. Disponível em: $<$ http://www.abpeducom.org.br/2014/08/anais-do-v-encontro-brasileiro-de.html>. Acesso em: 16 out. 2014.

MIRANDA, A.S. O Jornal Escolar e a Educação Problematizadora: vislumbrando uma aproximação. UNIrevista, v. 1, n. 3, 2006. Disponível em: $<$ http://www.alaic.net/ponencias/UNIrev Miranda.pdf >. Acesso em: 22 jan. 2014.

MOGADOURO, C.A.; SOARES, I.O. Educomunicação e escola: o cinema como mediação possível (desafios, práticas e proposta). Tese de Doutorado na área de Interfaces Sociais da Comunicação. São Paulo: USP, 2011.

NAPOLITANO, M. Como usar a televisão na sala de aula. 4. ed. São Paulo: Contexto, 2002. 
OLIVEIRA, M.E.; GONÇALVES, R. Por dentro de uma Oficina de Vídeo: Educomunicação e Audiovisual. In: XIII Congresso de Ciências da Comunicação na Região Sudeste - 07 a 10 de maio de 2008. Anais... São Paulo, maio 2008. Disponível em:

<http://www.intercom.org.br/papers/regionais/sudeste2008/expocom/EX9-0640-

1.pdf>. Acesso em: 14 set. 2014.

OROZCO-GÓMEZ, G. Comunicação, educação e novas tecnologias: tríade do século XXI. In: CITELLI, A.O.; COSTA, M.C.C. (Orgs.). Educomunicação: construindo uma nova área de conhecimento. São Paulo: Paulinas, 2011.

ROSA, R. Educomunicação e cidadania comunicativa: Formação de educomunicadores para o projeto Mais Educação, no Rio Grande do Sul (parceria entre a UFSM e a SEDUC/RS). In: V Encontro Brasileiro de Educomunicação: SOARES, I.O.S.; VIANA, C.E.; XAVIER, J.B (Orgs.). Anais... São Paulo: ABPEducom, p. 193-195, set. 2014. Disponível em: <http://www.abpeducom.org.br/2014/08/anais-do-v-encontro-brasileiro-de.html>. Acesso em: 16 out. 2014.

SAYAD, A.L.V. Idade mídia: a comunicação reinventada na escola. São Paulo: Aleph, 2011.

SANTOS, J.F. Educomunicação: uma inter-relação entre educação e comunicação. Revista Letrando, v. 2, 2013. Disponível em: $<$ http://revistaletrando.com/revista/volume2/11.Jonathas.pdf $>$. Acesso em: 28 ago. 2014.

SARTORI, A.S.; SOUZA, K.R.; KAMERS N.J. Desenho animado, TV e Youtube: reflexões sobre educomunicação e linguagens. In: XXXIII Congresso Brasileiro de Ciências da Comunicação - 2 a 6 de setembro de 2011. Anais... Recife, PE, set. $2011 . \quad$ Disponível em: <http://www.intercom.org.br/papers/nacionais/2011/resumos/R6-0788-1.pdf >.

Acesso em: 10 set. 2014.

SOARES, I.O. Educomunicação: o conceito, o profissional, a aplicação: contribuições para a reforma do ensino médio. São Paulo: Paulinas, 2011.

SOARES, I.O. Educomunicação: um campo de mediações. In: CITELLI, Adilson Odair; COSTA, Maria Cristina Castilho (Orgs.). Educomunicação: construindo uma nova área de conhecimento. São Paulo: Paulinas, 2011.

SOARES, I.O. Educomunicação. Youtube, 2012a. Disponível em: <http://www.youtube.com/watch?v=8iMyk4ddXZI >. Acesso em: 17 maio 2014.

SOARES, I.O. Estudos de educomunicação. Youtube, 2012. Disponível em: <http://www.youtube.com/watch?v=vz8a2xHb17M>. Acesso em: 17 maio 2014.

VASCONCELOS, M.L. Educação básica: a formação do professor, relação professor-aluno, planejamento, mídia e educação. São Paulo: Contexto, 2012.

XAVIER, A.N.O; SOLEDADE, J.S. A "leitura" do audiovisual e a formação do cidadão crítico. In: II Encontro de Educomunicação da Região Sul - 27 e 28 de junho de 2013. Anais... ljuí, RS, jun. 2013. Disponível em: <http://coral.ufsm.br/educomsul/2013/com/gt3/2.pdf >. Acesso em: 15 out. 2014. 